\title{
Relationship between Perceptions of Inter-parental Conflicts and Involvement in Delinquent Behaviours among Selected Kenyan Adolescent Students
}

\author{
*Dr. Kariuki, N. Scolastica \\ Kariuki Department of Education, School of Human and Social Sciences, \\ Daystar University. P.O. BOX 44400-00100, Nairobi Kenya \\ Email: skariuki@daystar.ac.ke \\ Dr. Peter J.O. Aloka \\ Jaramogi Oginga Odinga University of Science \& Technology, Kenya \\ Prof. Haniel Nyaga Gatumu \\ University of Nairobi, Kenya \\ Dr. Ciriaka Gitonga
}

Pan African Christian University, Kenya

\section{Doi:10.5901/jesr.2015.v5n1p25}

\section{Abstract}

\begin{abstract}
This study examined the relationship between adolescents' perceptions of parents' behaviours and their involvement in nonillegal and minor illegal delinquent behaviours in Secondary Schools, Nairobi Kenya. The study adopted a co-relational survey design. Questionnaires and a behaviour check list were used to gather data among students selected by stratified and simple random sampling. Data analysis was done by doing correlation. The findings showed that, perceived parental conflicts and non-illegal delinquent behaviours was $\left.r\left(.157^{* *}\right)=.001, p<.01\right)$, while the correlation between perceived parental conflicts and minor-illegal behaviour was $r(.049)=.325, p>.01$, and parental conflicts and generalised delinquency was $r(.124)=.012, p<$ .01. That is, there was significant positive relationship between high level Inter-parental conflicts and adolescents' involvement in non-illegal delinquent behaviours and generalised delinquency. However, inter-parental conflicts are not significantly related to adolescents' involvement in minor-illegal delinquent behaviours. The study recommended parental psycho-education in schools toward reducing conflicts and preventive and remedial counselling for adolescents involved in delinquency or exposed to the conflicts.
\end{abstract}

Keywords: relationship, adolescents, perceptions, parents, Inter-parental Conflicts, delinquency, secondary schools.

\section{Introduction}

The incidences of juvenile delinquency in Kenya have been on a steady increase in the recent years (Muola, Ndung'u \& Ngesa, 2009). Gategi, (2008) add that crime in Kenya has been on the increase in the last ten years. Aloka (2012) reiterates that, the behaviour problems interfere with the adolescents' academic, social, moral and physical development. It has been realized that most of the adolescent problems arise from family challenges. The Children Act (Cap. 586), Laws of Kenya PART III, spells out parents' responsibility on their children; Parents should provide of adequate diet, shelter, clothing, medical care, and education and guidance. As such it is assumed that when a child behaves in antisocial ways, the parents are liable for their children's conduct. Juvenile delinquency impacts negatively on children's education as shown by Davis and Jordan (1995). The researchers' have shown the academic and social challenges that face US schools as a result of children's nonconforming behaviours. They also note that delinquent adolescents suffer disproportionate numbers of suspension and expulsions and have poor academic performance. The adolescents avoid academic engagements; have low completion rates and exhibit decreased college attendance rates. McCoy and Reynolds (1992) in their report on Chicago adolescents noted that delinquency is one of the causes of grade retention and lower educational attainment 
For example, Matherme and Thomas (2001) argue that, family cohesion successfully predicts the frequency of delinquent acts for non traditional families. That is, families that are ridden with conflicts are also likely to fail in meeting their children's needs. Buehler \& Gerard, (2002) reiterates that, poor adolescents' adjustment has been linked to high levels of parental conflict and the associated tendency for them to be more hostile, aggressive, withdrawn, inconsistently controlling and disciplining as well as having a poor relationship with their adolescent. Over all, the adolescents in such conflict ridden families tend to develop a negative attitude towards one or both of their parents. The negative relationship tends to disrupt the meeting of the adolescents' needs. Furthermore, teenagers who experience family conflicts tend to ignore the behavioural demands of their parents. In addition, this unhealthy family climate is likely to lead to adolescents' indulgence in delinquent conducts.

Inter-parental conflict have been found to be significant determinates of children's behavioural and social maladjustment (Grych, \& Fincham, 2001; Arnett, 2004; Davies \& Lindsay, 2004; Houseknecht \& Hongo, 2006). The conflicts tend to disrupt the expected parental role of protecting, providing and loving their children. Children who are exposed to the conflicts tend to become targets of parents' physical and psychological hostility. The punitive parental behaviour is likely to make it difficult for children make rational behaviour choices. In addition, adolescents in hostile family climate are unlikely to obey rules or conform to behaviour expectation of parents who are hostile to them. Adolescents' perceptions about their parents are likely to influence their behaviours, in fact, the mental impressions they hold affects their decisions and judgments (Olivola \& Todoroy, 2010a, and 2010b). The perceptions about their parents can be used to predict their actions (Premack \& Woodruff, 1978). As adolescents interact with their parents they develop a theory of mind about the significant others' behaviours. The perceptions they hold are likely to determine how they behave. It has been observed that adolescents whose parents engage in high level conflict tend to experience more behavioural adjustment problems than their counterparts whose experience less conflict (Amato, 2000).

The preceding discussion indicates that many researchers have positively related inter parental conflicts with children's maladjustment. However, in Kenya the association between parental conflict and adolescents' behaviours is not clear. The researcher therefore sought to find out the relationship between adolescents' perceptions of parents' conflicts and their involvement in non-illegal and minor illegal delinquent behaviours.

\section{Theoretical Framework and Literature Review}

The study was guided by three theories, thus, parenting models (Baumrind, 1991), social control theory (Nye Ivan, 1958) and ego identity versus role confusion theory (Erik Erikson, 1980).

\subsection{Parenting models (Baumrind, 1991)}

Inferring from the model, it was hypothesised that adolescents' who perceived supportive parenting were likely to be less delinquent than those who viewed them as less supportiveness. Adolescents who perceive excessive monitoring are likely to sense authoritarian control while those who view their parents as not exercising concern and care could perceive permissiveness control. Baumrind (1991) model expresses moderate support and control as the ideal parenting that is likely to yield well adjusted children). Interparental conflicts are likely to disrupt parenting behaviours and thus lead to children receiving inadequate or excessive support. In addition, the theory shows that parental conflict can lead to parents over or under monitoring their adolescents. Furthermore, marital hostility is also likely to lead parents to be coercive, over restrictive, use harsh punishment discipline techniques and withdrawal love. Healthy marital adjustment is likely to allow opportunity to practice authoritative parenting. The adolescents whose parents use more of authoritarian or permissive approaches as opposed to authoritative parenting are likely to engage more in antisocial behaviour. According to the theory, both authoritarian and permissive parenting tends to evoke frustration and a poor parentadolescent relationship. Children who are raised in hostile families tend to seek sensational behaviours and peer affiliation with adolescents who are antisocial. Parental conflicts as thus likely to be linked with adolescents' involvement in delinquent behaviours.

\subsection{Social Control Theory (Nye Ivan, 1958)}

The theorist presumes that children are inherently delinquent and so for them to develop behaviour conformity they need some control. According to the theory, parental failure to control the child, whether real or perceived by the child can lead him or her to be involved maladaptive behaviours. Nye expresses four family controls approaches that impacts on 
children's behaviour. First, parents use direct control; this involves checking, rewarding, supervising, putting sanctions, disapproving and excluding techniques. Such direct measures are likely to be effective when parents supervise their children's behaviour and when adolescents expect rewards or punishment for their conduct. Such measures require a psychologically alert parent. At adolescence, the direct controls are likely to be perceived as harsh and excessive; as such adolescents may become angry and resentful to the parents. Weakened parent-adolescent bond may lead to adolescents' higher likelihood to be attracted to delinquent peers and to adopt their antisocial behaviours.

The second approach involves internal control. It involves inductive reasoning that includes training and giving explanations of behaviour consequences to children. Adolescents tend to internalise these trainings and accept the norms and rules as their guiding principle. As such a common morality in the family develops. Such adolescents develop both conscience and self-control which guides and guards them against antisocial behaviours. These adolescents are therefore more likely to behave in prosocial ways even when unsupervised. However when the parents experience inter conflict, they are unlikely to exercise inductive reasoning and therefore may be unable to draw the children into a common family morality. If common morality is lacking in the family the adolescent are likely to perceive the discrepancy between parental demands and the expected behaviours.

The third control according to the theory is the indirect control; In this case, children behave in desirable ways to appeal to significant others. A strong attachment bond is therefore necessary for children's avoidance of undesirable behaviour. Loving and supportive parents thus elicit their children's conformity to social rules. In contexts where parents experience high level conflict, the bonding, care and support for children tends to be relegated as second place. Adolescents from such parents are thus likely to engage in delinquency. Finally, the fourth control is a needs satisfaction control. This involves both internal and external control. In this case, parents seek to satisfy their children's needs and children develop an expectation that if they behave in expected ways their needs will be met and the reverse is also true. As such, children develop conscience associated with the meeting of their needs. A need for conformity arises from an innate tendency for fear of rejection by important others, a search for validation and a desire to have their needs met. Adolescents from conflict ridden families may not have a stable pattern of the combined internal and external control as illustrated. They may thus loose the attached basis for behaviour conformity and engage in antisocial behaviours.

The Social Control theory suggests that parental control, punishment and parent-child bonding can influence children's behaviours. If the child senses over controlling, excessive punishment and lack of affection, he or she can rebel against authority and become delinquent. Such punitive control measure and inadequate support tend to be common among conflicting parents and hence their adolescents are likely to be involved in delinquent behaviours.

\subsection{Ego Identity versus role confusion (Erik Erikson, 1980)}

The theory portrays adolescence as the stage in which children are actively seeking appropriate roles, values and vocations in an unconscious effort to self-definition. This exploration can results in either the adolescent finding a role commitment or identity confusion. Further, the theory depicts adolescents as actively seek new roles and statuses, those who explore without parental pushing are more likely to find a positive future path. Parents who fail to provide a clear path for their adolescents to choose from are likely to experience their children's excessive exploration. Erikson describes parents as influential in adolescents' formation of adaptive or maladaptive behaviour (identity achieved or identity confusion). Parents' negative reactions theirs' adolescents' exploratory behaviours can yield to rebellion and delinquency. The parents who experience marital conflicts are not likely to find time, resources and psychological strength to guide their adolescents. They are likely to use force or be permissive with them. Under such adolescents experiencing Interparental conflict are likely to develop identity confusion and thus become delinquent.

\subsection{Literature Review}

Adolescents whose parents engage high level conflict tend to experience more behavioural adjustment problems than their counterparts whose experience less conflicts (Amato, 2000). Parental conflict decrease parental warmth, support and also lead to reduced control of their children. In addition, adolescents experiencing marital conflicts have less warm parent- child relationship, increased verbal hostility and harsh punishment (Turner \& Kopiec, 2006; Bradford et al., 2007). High levels of inter parental conflicts tend to have negative implications on children especially when verbal and physical aggression occurs in their presence and when they are drawn to take sides. Adolescents who are from highly conflicting parents are more likely to be poorly adjusted compared to those who are not exposed to such (Kelly \& Emery, 2003; Kelly, 2007). 
Studies investigating parental conflict and adolescents' delinquency have been conducted. For example, Juby and Farrington (2001) investigated the relationship between disrupted families and delinquency, and found out that, family conflicts predicted high delinquency rate among boys from disrupted families. The replicated study in Switzerland shows that boys who remained with mothers but in less conflict had lower delinquency levels than those in conflicted families.

Larry, Brandunuc \& Welsh (2009) found out that, witnessing conflicts and violence is not different from being a victim. The study also reported that, witnessing conflict is more significant than being a target, and that, children who grow up in conflict- ridden homes are more involved in delinquency than children in low- level conflict. Krishnakumar et al. (2003) studied youth perceptions of parental conflict and their problems using a sample of 542 European-American and 150 African-American youth aged 10 through 18 years. Their findings showed that parental conflict was significantly related to youth problem behaviours in both European-American and African-American samples. Thus, parental conflict was linked with youth externalizing problem behaviours. Gerard et al. (2006) in a longitudinal research reported that, parental conflict is associated with adolescents' maladjustment through disruption in quality of parent-child relationship. Parental conflict resulted in punitive discipline, parental disengagement and negative parent-adolescents relationship. The study found direct association between parental conflict and externalizing problems in adolescents. Further, Cui et al. (2007) using a sample of 452 youths in early adolescence and their families examined reciprocal associations between marital problems and functioning and adolescent maladjustment. The findings revealed that parental conflict predicted adolescent delinquency.

Zinzow (2009) also examined parental violence as a risk for substance abuse and delinquency among adolescents in South California. Substance abuse as nonmedical drugs was assessed using the Diagnostic and Statistical Manual of Mental Disorders, fourth Edition (DSM-IV). Data was analysed using hierarchical regression. The results showed that, witnessing parental violence did not associate with substance abuse. However the focus of the study provided basis for investigating adolescents' perceptions of parental conflict. The current study extended the research to investigating the relationship between perceptions of parental conflicts and adolescents' non-illegal and minor-illegal delinquent behaviours.

Generally, there seems to be consensus findings among literature reviewed that inter parental conflicts are passively associated with adolescents' involvement in delinquent behaviours. Most of these studies are carried out in the developed world and may not be generalizable to Kenya and other similar status countries. As such, there was need to investigate the relationship between parental conflicts and their adolescents involvement in delinquent behaviours.

\subsection{Goal of the Study}

The study sought to examine the relationship between inter parental conflicts and their involvement in non-illegal and minor illegal delinquent behaviours among adolescents in Nairobi Secondary Schools in Nairobi, Kenya.

The following null and alternative hypotheses were tested:

$\mathrm{H}_{01}$ : There is no statistically significant relationship between adolescents' perceptions of parental conflicts and their involvement in non-illegal and minor-illegal delinquent behaviours.

$H_{a 1:}$ There is a statistically significant relationship between adolescents' perceptions of parental conflicts and their involvement in non-illegal and minor-illegal delinquent behaviours.

\section{Research Methodology}

\subsection{Research design}

The study adopted a quantitative research approach and a correlational design was used. Such a study requires a systematic and methodical approach to data collection and analysis (Koch and Harrington, 1998). Quantitative research also permits collection of numerical data (Jack and Clarke, 1998) which is amenable to statistical analysis (Carter, 2000a). The correlational survey design employed allowed the researcher to describe different events, experiences or behaviours and look for links between them (Shaughnessy, Zechmeister \& Jeanne, 2011). Correlational research design seeks to examine relationships between variables without introducing interventions (Nye, 1993). The design was thus appropriate as it allowed the researcher to describe data collected by means of a structured questionnaire and examine the relationship between independent variable (parental conflicts) and dependent variable( non-illegal and minor -illegal delinquent behaviours. Data was collected by using questionnaires and observation check lists. The adolescents' mean scores on the perceptions of parental behaviours and their involvement in delinquent conducts were correlated. 


\subsection{Study participants}

The population of study comprised of 49,728 adolescents; 26,755 boys and 22,973 girls according (EMIS, 2003-2007). Adolescents were stratified by gender using a list of 60 Nairobi public secondary which had registered for KCSE by the year 2010 (KNEC, 2010). Stratified and simple random sampling techniques were used to obtain a sample of 450 students from 5 schools. The techniques provide a sample that is highly representative of the population being studied (Nachmias \& Nachmias, 1987). A 10\% of a population comprises a representative sample (Gay, 1992), as such a final sample of 410 adolescents were considered adequate after $6.6 \%$ of the participants' questionnaires were excluded for low completion.

\subsection{Research instruments}

Questionnaires measuring adolescents' delinquency was used to collect data. For the instrument used in this research a Chronbach's Alpha reliability coefficient of 0.827 was obtained after taking the average of intercorrelations of the items categories for each variable as shown in Table 2. Self- report measures of delinquency with a reliability coefficient of about 0.8- 0.99 are acceptable (Huizinga \& Elliott, 1986).

\subsection{Data Collection Procedure}

The researcher obtained permission for data collection from Kenyatta University Graduate School and from the Kenyan Ministry of Education, Science and Technology. In addition, permission was sought from the school principals of the sampled schools. The researcher gave clear instructions to the Form 1 and 3 students who were issued with numbered questionnaires. After completion the instruments were collected and labelled for further processing. Before embarking on data collection, the researcher, explained to the participants the content and purpose of the research, and the free will to participate or to refrain from the exercise. In addition, confidentiality was promised and observed. The researcher ensured that the truth was presented without alterations and used for academia purpose only.

\subsection{Data Analysis}

Data on the perceived parental conflicts were summed up and mean scores were categorised as 2.56 - 3 (always), 1.46 2.45 (often); 1-1.45 (rarely) involved. The mean scores for non-illegal, minor-illegal and generalised delinquency ranged from lowest score of 1 to the highest score of 3. Adolescents involvement in delinquent behaviours mean score of 1-1.45 were considered as never involved (normative behaviour), $1.46-2.45$ was considered as occasionally involved while 2.46 - 3 was taken as persistently involved. Pearson Correlation Coefficient was computed to examine the relationship between adolescents' perceptions of parental conflicts and adolescents' non-illegal and minor illegal delinquent behaviours. A relationship was said to be significantly present if the $r$ or $r_{s}$ value had a corresponding $p$ value less than stated $a$ value. On the other hand, a relationship was said to be absent when the obtained $r$ or $r_{s}$ value had a corresponding $p$ value that was greater than the stated $\alpha$ value.

\section{Findings and Discussion}

\subsection{Demographic Characteristics of Respondents}

The study involved 410 participants who comprised $53.4 \%$ females and $46.6 \%$ male adolescents. The respondents comprise students in early adolescence (18.8\%), mid-adolescence (42\%) and late adolescence (35.6\%). A few cases were above age 18 and were $2.7 \%$ as shown in Table 1. 
Table 1: Adolescents' Demographic Data

\begin{tabular}{|c|c|c|c|}
\hline \multicolumn{2}{|c|}{ Variables } & Feq & $\%$ \\
\hline \multirow{3}{*}{ Gender } & Male & 191 & 46.6 \\
\cline { 2 - 4 } & Female & 219 & 53.4 \\
\cline { 2 - 4 } & Total & 410 & 100 \\
\hline \multirow{3}{*}{ Age } & $13-14$ & 77 & 18.8 \\
\cline { 2 - 4 } & $15-16$ & 176 & 42.9 \\
\cline { 2 - 4 } & $17-18$ & 156 & 35.6 \\
\cline { 2 - 4 } & Over 18 & 11 & 2.7 \\
\cline { 2 - 4 } & Total & 410 & 100 \\
\cline { 2 - 4 } & &
\end{tabular}

\subsection{Findings on Adolescents' perceptions of Inter-parental conflicts and their involvement in delinquent Behaviours}

The study examined the relationship between adolescents' perceptions of parental conflicts and their involvement in nonillegal and minor illegal delinquent behaviours. As shown in Table 2, some, 410 respondents indicated their perceptions of parental involvement in conflicts.

Table 2: Perceived Parental Conflicts and Adolescents' Delinquent Behaviours

\begin{tabular}{|c|c|c|c|c|c|c|c|c|}
\hline \multirow{2}{*}{ Parental Dispute } & \multicolumn{3}{|c|}{ None Illegal } & \multirow{2}{*}{ Total } & \multicolumn{4}{|c|}{ Minor illegal } \\
\cline { 2 - 6 } & Not involved & Occasionally & Persistently & & Not Never & Occasionally & Persistently & Total \\
\hline \multirow{2}{*}{ Rarely } & 17 & 178 & 24 & 219 & 107 & 107 & 0 & 219 \\
\cline { 2 - 6 } & $7.8 \%$ & $81.3 \%$ & $11.0 \%$ & $100 \%$ & $48.9 \%$ & $48.9 \%$ & $.0 \%$ & $100 \%$ \\
\hline \multirow{2}{*}{ Often } & 6 & 99 & 29 & 134 & 74 & 74 & 4 & 134 \\
\cline { 2 - 6 } & $4.5 \%$ & $73.9 \%$ & $21.6 \%$ & $100 \%$ & $55.2 \%$ & $55.2 \%$ & $3.0 \%$ & $100 \%$ \\
\hline \multirow{2}{*}{ Always } & 9 & 33 & 15 & 57 & 21 & 21 & 0 & 57 \\
\cline { 2 - 6 } & $15.8 \%$ & $57.9 \%$ & $26.3 \%$ & $100 \%$ & $36.8 \%$ & $36.8 \%$ & $.0 \%$ & $100 \%$ \\
\hline \multirow{2}{*}{ Total } & 32 & 310 & 68 & 410 & 202 & 202 & 4 & 410 \\
\cline { 2 - 6 } & $7.8 \%$ & $75.6 \%$ & $16.6 \%$ & $100 \%$ & $49.3 \%$ & $49.3 \%$ & $1.0 \%$ & $100 \%$ \\
\hline
\end{tabular}

The results show that the highest percentage of the adolescents who never got involved in non-illegal (15.8\%) delinquent behaviours perceived that their parents always had conflicts. The highest percentage of those who never got involved in minor-illegal delinquent behaviours (55.2\%) perceived that their parents often had conflicts. The lowest percentage of the adolescents who were never involved in non-illegal delinquent behaviours (4.5\%) perceived that their parents often had conflicts. On the other hand adolescents who perceived that their parents always had conflicts comprised the highest percentage of those who got involved in minor-illegal delinquent behaviours (36.8\%). Further, the highest percentage of the adolescent who got involved in occasional non-illegal (81.3\%) delinquent behaviours perceived that their parents rarely got involved in conflicts. The lowest percentages (57.9\%) of those who were engaged in occasional non- illegal delinquent behaviours perceived that their parents always had conflicts. In addition, the highest percentage of the adolescents who got involved in persistent non-illegal (26.3\%) delinquent behaviour perceived that their parents always had conflicts. The lowest percentage (11\%) of those who persistently got involved in non-illegal delinquent behaviours perceived that their parents rarely got involved in conflicts..

Further, the adolescents who perceived that their parents often had conflicts comprised the highest percentage $(55.2 \%)$ of those who engaged in occasional minor-illegal behaviours. Those who perceived that their parents had conflicts often comprised the lowest percentage (36.8\%) of adolescents who were engaged in occasional minor-illegal behaviours. Finally the highest percentage (3\%) of the adolescents who were involved in persistent minor-illegal behaviours comprised those who perceived that their parents often had conflicts.

The relationship between adolescents' perceptions of parental conflicts and their involvement in delinquent behaviours was examined further using Pearson Product Moment correlation. The alternative and null hypotheses were tested.

H01: There is no statistically significant relationship between adolescents' perceptions of parental conflicts and their involvement in non-illegal and minor- illegal delinquent behaviours.

$H_{a 1}$ There is a statistically significant relationship between adolescents' perceptions of parental conflicts and their 
involvement in non-illegal and minor- illegal behaviours.

As shown in Table 3, Pearson Correlation Coefficient" was computed at $\alpha=.01$ (two- tailed test). The relationship between perceived parental conflicts and non-illegal delinquent behaviours was $\left.r\left(.157^{\star *}\right)=.001, p<.01\right)$ while the correlation between perceived parental conflicts and minor-illegal behaviour was $r(.049)=.325, p>.01$, and parental conflicts and combined mean generalised delinquency at $r(.124)=.012, p<.01$. The alternative hypothesis ( $\left.\mathrm{Ha}_{4}\right)$ was adopted at $p<.01$ for parental conflicts and adolescents' non-illegal delinquent behaviours. It means that frequent parents' conflict significantly associated with increased adolescents' involvement in non-illegal delinquent behaviours. However, the null hypothesis $\left(\mathrm{H}_{04}\right)$ was retained for perceived parental conflicts and adolescents' minor-illegal and generalised delinquent behaviours at $p>.01$. This reveals that perceptions of parental conflicts are not significantly related to adolescents' involvement in minor-illegal delinquent behaviours on their own.

Table 3: Correlation between Perceived Parental Conflicts and Adolescents' Delinquent Behaviours

\begin{tabular}{|c|c|c|c|c|c|}
\hline \multicolumn{2}{|c|}{} & Parental Conflicts & Non- illegal & Minor-illegal & Mean Generalised Delinquency \\
\hline \multirow{3}{*}{ Parental Conflicts } & Pearson Correlation & 1 & $.152^{\text {** }}$ & .076 & .124 \\
\cline { 2 - 6 } & Sig. (2-tailed) & & .002 & .122 & .012 \\
\cline { 2 - 6 } & $\mathrm{N}$ & 410 & 410 & 410 & 410 \\
\hline
\end{tabular}

*. Correlation is significant at the .01 level (2-tailed).

The current study found that perceived parental disputes related to adolescents' non-illegal delinquent behaviours. The study also found that there is no relationship between adolescents' perceptions of parental minor-illegal delinquent behaviours. It can be argued that increased frequency of parental conflicts positively relates to adolescents' non-illegal and generalized delinquency. It is possible that parental conflicts evoke frustrations among their children. Some of the adolescents who experienced conflicts may have sought sensational experiences to alleviate their emotional states. Eventually they may have also engaged in behaviour explorations to make up for the frustrations. It concluded that increased perceptions of parental conflicts significantly positively relates to adolescents' involvement in non-illegal and generalized delinquency delinquent behaviours. Parental conflicts tend to evoke frustrations among children. Some of the adolescents who experienced parental conflicts may have sought sensational experiences to alleviate their emotional states. Eventually they may have also engaged in behaviour explorations to make up for the frustrations.

According to family systems theory, relationships among individuals in the family influence the family as a whole (Granic, Dishion \& Hollenstein, 2003; Steinberg \& Silk, 2002). It is therefore expected that parents who got into conflicts have some effect on their adolescents' behaviours. The findings on perceived parental conflicts are consistent with Cunning and Merrilees (2008). The researchers' findings reveal that adolescents who experience parental conflicts and violence between their parents display non-illegal delinquent behaviours. Further, Austin, Macgowan and Wagner (2005) findings indicate that high levels of conflict risk adolescents' involvement in behaviour problems. The findings converge with the current findings which reveal that parental conflicts significantly positively relate to adolescents' non-illegal and generalised delinquency. However, Zinzow (2009) in hierarchical regression study found that parental violence did not influence adolescents' substance abuse and violence. These current results diverge from Zinzow's findings which were rather surprising. The fact that the study was conducted in South California and that it employed hierarchical regression may have led to differential results. If adolescents' perceive parents' conflicts with each other as common and acceptable the behaviour is likely not to affect their behaviours. The implication is that, parental education should be enhanced on the behaviours of the adolescent students. Moreover, parents should be sensitized on providing a conducive home environment for the holistic development of students.

\section{Concluding Remarks}

The study examined the relationship between adolescents' perceptions of parental conflicts and their non-illegal, minorillegal delinquent behaviours and generalised delinquency. The results revealed that there was a significant positive relationship between parental conflicts and adolescents' non-illegal delinquent behaviours. However, there was no significant relationship between adolescents' perceptions of parental conflicts and their minor-illegal delinquent behaviours. The results also showed that, there was a significant positive relationship between adolescents' perceptions of parental alcohol use and their involvement in non-illegal, minor-illegal delinquent behaviours and generalised delinquency. Adolescents' perceptions of parental conflicts are significantly positively related to their involvement in nonillegal delinquent behaviours. However, perceptions of parental conflicts are not significantly related to adolescents' 
involvement in minor-illegal delinquent behaviours and generalised delinquency.

One of the limitations of the study is the use of adolescents' self-report measures on their perceptions of parental behaviours and involvement in delinquent conducts. Researchers have observed that adolescents tend to over-report issues that are likely to portray them as unique and independent (Noller \& Callan, 1988). To make up for this limitation, it is recommended that adolescents' self- report measures are used to gather data on less serious delinquent behaviours (Babinske, Hartsough, \& Lambert, 2001). In response to the observations the researcher ensured that the examined delinquent behaviours did not include serious delinquent conducts. The second limitation was non-inclusion of parents' views and the use of adolescents' perceptions only. The approach was judged as appropriate because most previous researches on youths' delinquency have relied on estimates of interpersonal influences based on the adolescents' perceptions of their significant others' attributes (Mark, Denise \& Kandel 1981). The third limitation was that this study focused on the joint perceptions attached to both parents as a unit rather than focusing attention on the mother and the father independently. This was done with the full knowledge that adolescents respond in different ways to their mothers and fathers. The joint focus has been used in past studies. For example, Arim, Marshall, Shapka (2009) used the method in a study on approaches to adolescent reporting of parental control. Saskia Wijsbroek, William, Hale III, Quinten, Raaijmakers, and Wim (2011) also used the method to study perceived parental behavioural and psychological control and adolescents' self-reported anxiety disorders symptoms. The intent of the researcher in using this method is to capture the general perceptions of parental behaviour in the family.

Based on the results, help for delinquent adolescents should include parental psycho-education. This is because adolescents who involved in non-illegal (noncompliance and truancy) and generalised delinquency were those who perceived parental excessive monitoring, punitive discipline, frequent conflicts, and alcohol use. Parenting education would reduce chances of parents' over monitoring their adolescents' alleviate use of harsh words, engage in less conflicts and avoid alcohol use. Moreover, parental conflicts should be avoided. This is because it was reported that, adolescents' perceptions of increased parental monitoring are significantly positively related to their minor-illegal delinquent behaviours and involvement in generalised delinquency. It was also recommended that there is need for teachers to provide parenting training skills to alleviate excessive monitoring, punitive discipline, parents 'conflicts and alcohol use in the family, the approach would alleviate adolescents' involvement in delinquent behaviours. Finally, the Kenyan Ministry of Education should ensure that secondary schools have professional counsellors, educational psychologists and adequate facilities that will enable effective counselling for delinquent adolescents and those with perceptions that have been found to link with involvement in delinquency.

\section{References}

Aloka, (2012).Group polarization in decision making: a study of selected Kenyan secondary school disciplinary panels. Published PhD Thesis. Faculty of Education. University of the Western Cape, Cape town.

Amato, P.R. (2000). The consequences of divorce for adults and children. Journal of Marriage and the Family, 62, 1269-1287.

Arnett, J.J. (2004). Adolescence and emerging adulthood: A cultural approach. (2nd.Ed). New Jersey, Pearson Education.

Austin, A. M., Macgowan, M. J., \& Wagner, E. F. (2005). Effective family based interventions for adolescents with substance use problems: A systematic review. Research on Social Work Practice, 15, 67-83.

Austin, A. M., Macgowan, M. J., \& Wagner, E. F. (2005). Effective family based interventions for adolescents with substance use problems: A systematic review. Research on Social Work Practice, 15, 67-83.

Babinski, L M., Hartsough, C. S., \& Lambert, N. M. (2001). A comparison of self-report of criminal involvement and official arrest records. Aggressive Behaviour, 27 (1), 44-54.

Bradford, K., Burns Vaughn, L., \& Barber, B.K. (2007). When there is conflict: Inter parental conflict, parental child conflict, and youth problem behaviours. Journal of Family Issues, 29(6), 780-805.

Buehler, C., \& Gerard, J. M. (2002). Marital conflict, ineffective parenting, and children's and adolescents' maladjustment. Journal of Marriage and the Family, 64, 78-92.

Carter, D. E. (2000). Quantitative research: The Research Process in Nursing (4th ed.). Oxford: Blackwell Science Ltd.

Cunnings, E. M., Merrilees, E. C., \& Kouros, C. D. (2008). Identifying the dynamic processes of underlying links between marital conflict and child adjustment. Washington DC: American Psychological Association.

Cui, M., Donnellan, M.B., \& Conger, R.D. (2007). Reciprocal influences between parents' marital problems and adolescent internalizing and externalizing behavior. Developmental Psychology, 43(6), 1544-1552.

Davies, P.T., \& Lindsay, L.L. (2004). Inter parental conflict and adolescent adjustment: Why does gender moderate early adolescent vulnerability. Journal of Family Psychology, 18(1), 160-170.

Davis, E. R. \& Jordan J. W. (1995). Effects of school contexts, structure, and experiences on African American males in middle and high school. Journal of Negro Education, 63(.4) 66-70.

Davis \& Virginia (2007). Journal of child development, university of California, polytechnic Institute and Stage University. 
EMIS Kenya, (2007). Educational statistical booklet. Ministry of Education.

Gay, L. R. (1992). Educational research: Competence for analysis and application. (4th ed.). New York: Macmillan Publishers.

Gecas, V., \& Schwalbe, M.L., (1986). Parental behavior and adolescent self-esteem. Journal of Marriage \& Family, 48, 37-46.

Gerard, J.M., Krishnakumar, A., \& Buehler, C. (2006). Marital conflict, parent-child Relations, and youth maladjustment: A longitudinal investigation of spill over effects. Journal of Family Issues, 27(7), 951-975.

Gerard, J.M., Krishnakumar, A., \& Buehler, C. (2006). Marital conflict, parent-child Relations, and youth

Granic, I, Dishion, T. J, \& Hollenstein, T. (2003). The family ecology of adolescence: A dynamic systems perspective on Normative development Malden: Blackwell

Grych, J. H., \& Fincham, F. D. (2001). Inter-parental conflict and child development: theory, research, and applications. New York: Cambridge University Press.

Houseknecht, S.K., \& Hongo, D.W. (2006). The impact of marital conflict and disruption on children's health. Youth and Society, 38(1), 753-756

Jack, B., \& Clarke, A. M. The strengths and weaknesses of research designs involving quantitative measures. Journal of research in nursing, 38(5), 229-239

Juby, H., \& Farrington, D.P. (2001). Disentangling the link between disrupted families and delinquency. Brit Journal Criminal, $41,22-40$.

Kelly, J.B., \& Emery, R.E. (2003). Children's adjustment following divorce: Risk and Resilience perspectives. Family Relations, 52, 352362.

Kevin R. Bush, Gary W. Peterson, José A. Cobas, Andrew J. Supple (2003). Adolescents' Perceptions of Parental Behaviours as Predictors of Adolescent Self-Esteem in Mainland China Retrieved from http://onlinelibrary.wiley.com/doi/

Koch, T., Harrington, A. (1998) Reconceptualising rigour: the case for reflexivity. Journal of Advanced Nursing 28:4, 882-890.

Krishnakumar, A., Buehler, C., \& Barber, B.K. (2003). Youth Perceptions of Interparental Conflict, Ineffective Parenting, and Youth Problem Behaviours in European-American and African-American Families. Journal of Social and Personal Relationships, 20(2), 239-260.

Laws of Kenya (2001). Children Act (Cap. 586), Nairobi: GOK.

McCoy, R. A., \& Reynolds, J. (1992). Grade retention and school performance: An extended investigation. Journal of Social Psychology vol 37(3), 7- 15, USA University of Wisconsin-Madison.

Mark. D, Denise \& B. Kandel (1981). Parental and Peer influences on Adolescents' Educational Plans: Some Further Evidence. American Journal of Sociology (87)2, Retrieved from http://www.jstor.org/discove.

Muola, J. M., Ndungu, N. M., \& Ngesa, F. (2009). The Relationship between family functions and juvenile delinquency. A case of Nakuru Municipality. Kenya. African Journals Online Retrieved from http://www.ajol.infosays.

Noller, P., \& Callan, V. J. (1988). Understanding parent- adolescent interaction: Perceptions: Perceptions of family members and outsiders. Journal of Developmental Psychology, 24(5), 707-714

Nachmias C. F. \& Nachmias, D. (1987). Research Methods in the Social Sciences (5th ed). New York: St. Martin's Press.

Olivola, C, Y, \& Todorov A (2010a). Fooled by first impressions? Re-examining the diagnostic value of appearance-based inferences. Journal of Experimental Social Psychology, 46:315-24.

Olivola C, Y \& Todorov (2010b). Elected in 100 milliseconds: appearance-based trait inferences and voting. Journal of Nonverbal Behavior 2010b; 34:83-110.

Peterson, Gary W., and D. Hann. 1999. Socializing Parents and Families, Pp. 327-70 in Handbook of Marriage and the Family, New York: Plenum.

Premack, D, \& Woodruff, G. (1978). Does the chimpanzee have a theory of mind?. Behavioural and brain sciences, (1)04, 515-526.

Saskia A. M. Wijsbroek, William W. Hale III, Raaijmakers Quinten A. W. RaaijmakersQuinten A. W. Raaijmakers, and Wim H. J. MeeusWim H. J. Meeus (2011). The direction of effects between perceived parental behavioural control and psychological control and adolescents' self-reported GAD and SAD symptoms. Eur Child Adolesc Psychiatry July; 20(7): 361-371.

Shaughnessy, J. J., \& Zechmeister, B. E., \& Jeanne, S. Z. (2011). Research methods in psychology (9th ed.). New York: McGraw-Hill

Steinberg, L. \& Silk, J. S. (2002). Parenting Adolescents. In M. H. Bornstein (ed.), Handbook of parenting. Vol1: Children and parenting (2nd ed.) Mahwah, NJ: Lawrence Ealbau Associates, 103-33.

Streubert, H.J., Carpenter, D.R. (1999) Qualitative Research in Nursing: Advancing the Humanistic Imperative (2nd ed.). Philadelphia: Lippincott.

Turner, H.A., \& Kopiec, K. (2006). Exposure to inter parental conflict and psychological disorder among young adults. Journal of Family Issues, 27(2), 131-158.

Tye, C. (1993) Qualified nurses' perceptions of the needs of suddenly bereaved family members in the accident and emergency department. Journal of Advanced Nursing 18: 948-956.

Zinzow, M. H (2009). Witnessed community and parental violence in relation to delinquency in a national sample of adolescents. Journal of Traumatic Stress, vol. 22, No. 6. 
